\title{
СЕЛЬСКИЙ ТУРИЗМ В ПЕРИОД СОЦИАЛЬНО-ЭКОНОМИЧЕСКИХ ТРАНСФОРМАЦИЙ ${ }^{1}$
}

\section{RURAL TOURISM UNDER SOCIO-ECONOMIC TRANSFORMATION}

A. Gamidova

V. Plotnikov

Summary. Rural tourism is relatively recently introduced into the legal space of the Russian Federation. This requires its broader theoretical understanding. Although rural tourism de facto existed before, the organization of its legal regulation requires a more accurate understanding of this phenomenon. The article examines the essence of rural tourism, gives its expanded author's interpretation, studies the prospects for its development in the conditions of socio-economic transformations caused by the Covid-19 pandemic.

Keywords: rural tourism, socio-economic development, state regulation of the economy, socio-economic transformation.
Гамидова Ариза Элдикаровна

Директор, Махачкалинское представительство Московского финансово-промышленного университета «Синергия» uglana2013@mail.ru

Плотников Владимир Александрович Профессор, Юго-Западный государственный университет

Plotnikov_2000@mail.ru

Аннотация. Сельский туризм сравнительно недавно введен в правовое пространство Российской Федерации. Это требует его более широкого теоретического осмысления. Хотя сельский туризм де-факто существовал и ранее, организация его правовой регламентации требует более точного понимания этого феномена. В статье рассмотрена сущность сельского туризма, дана его расширенная авторская трактовка, изучены перспективы его развития в условиях социально-экономических трансформаций, вызванных пандемией Covid-19.

Ключевые слова: сельский туризм, социально-экономическое развитие, государственное регулирование экономики, социально-экономическая трансформация.

ознакомления с деятельностью сельскохозяйственных товаропроизводителей и (или) участия в сельскохозяйственных работах без извлечения материальной выгоды с возможностью предоставления услуг по временному размещению, организации досуга, экскурсионных и иных услуг. Деятельность по оказанию услуг в сфере сельского туризма осуществляется сельскохозяйственными товаропроизводителями в соответствии с требованиями, установленными Правительством Российской Федерации».

Изменение ситуации с правовым регулированием сельского туризма требует дополнительных исследований его сущности и форм проявления, чему и посвящена данная статья. Значимость ее проблематики определяется и тем, что прошедший 2020 год «отметился» не только пандемией Covid-19, он также был объявлен Генеральной ассамблеей Всемирной туристской организации ООН «Годом сельского и экологического туризма». ностью населения до тридцати тысяч человек, в целях отдыха, приобщения к традиционному укладу жизни, 


\section{Анализ сушности} сельского туризма

Несмотря на имеющееся в федеральном законодательстве определение сельского туризма, к анализу которого мы еще вернемся, различные специалисты предлагают собственные трактовки этой категории.

Так, например Волков С.К., указывает, что «суть данного вида туризма заключается в отдыхе в сельской местности, где всё организационное обеспечение проживания туристов (в том числе питание, досуг, обслуживание и др.) берёт на себя принимающая семья» [1, с. 31]. Важно отметить, что в трактовке этого специалиста сельский туризм, с позиций производства соответствующих услуг, является индивидуально-направленным, семейным, для его осуществления используются не ресурсы каких-либо организаций, но ресурсы домохозяйств (сельских семей). Этим из сферы сельского туризма исключаются собственно туристические фирмы, что, по нашему мнению, некорректно.

По мнению Трухачева А.В., «сельский туризм следует рассматривать, как обобщающее понятие, объединяющее различные виды организованного и самодеятельного туризма, реализуемые в сельской местности» [20, с. 34]. То есть, в данном случае родовым признаком сельского туризма выступает локализация соответствующей дестинации, а не содержание собственно туристических услуг. Формально говоря, исходя из данного подхода, сельский туризм выступает антиподом туризма городского (оба они осуществляются на суше) и водного (морского, озерного, речного, осуществляемого В той или иной акватории). Таким образом, по нашему мнению, искажается его сущность.

Как указывают Гварлиани Т.Е. и Бородин А.Н., «сельский туризм - группа функциональных видов туристской деятельности, которые могут осуществляться в сельской местности и включают деятельность лиц, находящихся за пределами их обычной среды, путешествующих и осуществляющих пребывание в данной местности для отдыха и с другими целями» [6, с. 64]. Здесь так же, как и у предыдущего рассмотренного автора, присутствует явное тяготение в определении сельского туризма к территориальному признаку, локализации дестинаций сельского туризма. И это определение, помимо высказанной выше критики, также несовершенно. В частности, требуют раскрытие «другие цели», ведь пребывание в сельской местности может не быть связано с туризмом (пример - посещение горожанами родственников, живущих в деревне, в ходе которого отсутствуют рекреационные мотивы, присущие туризму, как социально-экономическому явлению).
Достаточно корректным, с научных позиций, по нашему мнению, является утверждение Здорова А.Б.: «Понятие аграрного (сельского) туризма можно трактовать двояко. В узком смысле под аграрным туризмом понимают отдых городских жителей в сельской местности, предполагающий более или менее длительную аренду загородного жилья. В широком смысле аграрный туризм включает все виды времяпрепровождения городских жителей в сельской местности, т.е. элементы отдыха и оздоровительных мероприятий. В частности, в данном случае речь может идти о сочетании отдыха с трудом на приусадебном участке, об этнографических экскурсиях с акцентом на сельскую составляющую, о добровольном временном участии в агропроизводстве в рамках рекреационных мероприятий» [8, с. 149]. Хотя использованное этим автором отождествление сельского и аграрного туризма, на наш взгляд, не соответствует внутреннему содержанию этих видов туризма, которые, хотя и близки, но все же имеют некоторые отличия.

Подобный анализ можно продолжить, т.к. проблематике сельского туризма посвящено довольно много исследований, в том числе авторских [3, 15, 18, 19, 21, 23 и др.]. Но задача научного исследования состоит не в перечислении тех или иных положений, пусть даже сопровождаемом авторским анализом, но в разработке новых теоретических и методических конструкций. В этой связи, далее мы непосредственно перейдем к предлагаемому нами определению сельского туризма. При этом в качестве основы мы используем тот вариант трактовки сельского туризма, который предложен в Федеральном законе от 02.07.2021 г. № 318-Ф3.

\section{Авторское понимание сельского туризма}

Итак, по нашему мнению, сельским является туризм, предусматривающий посещение (нахождение) людьми сельской местности в целях отдыха, приобщения к традиционному укладу жизни, ознакомления с деятельностью сельскохозяйственных товаропроизводителей, участия в сельскохозяйственных работах без извлечения эквивалентной материальной выгоды и другими; деятельность по оказанию услуг в сфере сельского туризма осуществляется как туристическими фирмами, так и сельскохозяйственными и иными организациями и физическими лицами.

К сформулированному определению следует сделать некоторые дополнения:

1. Можно согласиться с предложенной законодателем трактовкой, в рамках которой к сельской местности относятся и малые города, так как социальный уклад и структура хозяйственной 
активности в малых городах, как правило, ближе к аналогичным характеристикам сельских поселений, чем крупных городов. Для формализации понятия «малый город» использован признак предельной численности населения до тридцати тысяч человек. Но признак этот условный, т.к. характеристики конкретного города, хотя и связаны с численностью его населения, тем не менее, полностью ею не определяются. Например, малые моногорода и поселки в Заполярье или иных суровых климатических условиях не имеют рассмотренных выше социальных и экономических признаков, присущих сельской местности.

2. Мы намеренно, как и ряд авторов, мнения которых анализировались выше, не ограничили перечень мотивов сельского туризма, что, хотя и «размывает» предложенное определение, делает его менее строгим, но, с другой стороны, позволяет давать расширительную трактовку сельскому туризму, включать в него те виды времяпрепровождения, которые не упомянуты в федеральном законе. Ведь, например, сельский турист может быть заинтересован не в «приобщении к традиционному укладу жизни», а в ознакомлении с местными этнически окрашенными традициями, к которым он не планирует «приобщаться», но желает их детальнее изучить. Или, например, знакомиться в сельской местности можно не только с деятельностью «сельскохозяйственных товаропроизводителей», но и тех организаций и физических лиц, которые заняты ремесленным производством, выполнением работ и оказанием услуг промежуточного характера, напрямую не направленных на производство сельскохозяйственной продукции.

3. Отдельного упоминания заслуживает «участие в сельскохозяйственных работах без извлечения материальной выгоды», упомянутое в федеральном законе. Такой тезис вполне понятен и очевиден. Цель его введения - отграничить от туризма тех лиц, которые приезжают в сельскую местность на заработки, например, для участия в уборке урожая различных сельскохозяйственных культур. Но, в то же время, такая формулировка фактически налагает запрет на получение тех или иных материальных выгод сельскими туристами от их вовлечения в процессы трудовой сельской деятельности. Например, соучастие сельского туриста в выпечке хлеба в русской печи может (и это весьма ожидаемо, с позиций туриста) в дальнейшем сопровождаться употреблением (естественно - без оплаты) этого хлеба. Аналогичные примеры могут касаться участия туриста в доении коровы, сборе урожая фруктов и т.д. Формально говоря, турист в этих случаях получает материальную выгоду, натуральную оплату своего труда. Очевидно также, что эта натуральная оплата не соотносится с понесенными трудозатратами, она не является эквивалентной. Именно поэтому в представленном определении предлагается вести речь об отсутствии извлечения именно «эквивалентной материальной выгоды».

4. Сельский туризм предполагает временное нахождение туристов в сельской местности. Этот тезис поддерживается большинством авторов, мнения которых мы анализировали, на это же указывает и формулировка федерального закона, в которой говорится о «возможности предоставления услуг по временному размещению, организации досуга, экскурсионных и иных услуг». Но это именно «возможность», а не обязательное требование. И эта возможность является не чем-то особенным, она присуща всем видам туризма, а не только сельскому. В этой связи включение этого элемента в определение не является, по нашему мнению, необходимым.

5. Интересный вопрос - кто может быть субъектом сельского туризма как вида хозяйственной деятельности? В одном из рассмотренных нами определений это - сельские домохозяйства, в законодательной трактовке - специально отобранные и сертифицированные сельскохозяйственные товаропроизводители. Такой подход, основанный на намеренном ограничении субъектов сельскохозяйственного туризма, по нашему мнению, непродуктивен. По сути, речь идет о намеренном, ни на чем не основанном ограничении конкуренции [16], что может привести к снижению качества и повышению цен на услуги сельского туризма, а также к неполному использованию или же вовсе неиспользованию имеющихся в России рекреационных ресурсов сельского туризма. В этой связи целесообразно более широко привлекать в сферу сельского туризма не только сельхозтоваропроизводителей, которые зачастую не имеют для этого достаточных ресурсов и мотивации, но и туристические фирмы, обладающие необходимыми компетенциями, а также самих сельских жителей, в том числе горожан, временно проживающих в сельской местности.

\section{Трансформация \\ социа^ьно-экономической системы и развитие сельского туризма}

Сельский туризм - перспективное направление развития туризма, что обусловлено его большей устой- 
чивостью, в сравнении с другими видами туризма, к шоковым макроэкономическим воздействиям. Особенно ярко это проявилось в период развития пандемии Covid-19. Пандемия и связанное с ней ограничение мобильности населения нанесли значительный ущерб развитию туризма $[4,5,7]$.

Туризм отнесен к числу наиболее пострадавших от пандемии отраслей. К ним, согласно постановлению Правительства РФ от 03.04.2020 г. № 434 «Об утверждении перечня отраслей российской экономики, в наибольшей степени пострадавших в условиях ухудшения ситуации в результате распространения новой коронавирусной инфекции», отнесены:

1. Транспортная деятельность.

2. Культура, организация досуга и развлечений.

3. Физкультурно-оздоровительная деятельность и спорт.

4. Деятельность туристических агентств и прочих организаций, предоставляющих услуги в сфере туризма.

5. Гостиничный бизнес.

6. Общественное питание.

7. Деятельность организаций дополнительного образования, негосударственных образовательных учреждений.

8. Деятельность по организации конференций и выставок.

9. Деятельность по предоставлению бытовых услуг населению (ремонт, стирка, химчистка, услуги парикмахерских и салонов красоты).

10. Деятельность в области здравоохранения.

11. Розничная торговля непродовольственными товарами.

12. Средства массовой информации и производство печатной продукции.

В силу того, что собственно туризм (п. 4 вышеприведенного перечня) способствует кластерообразованию $[11,14,22]$, негативное влияние его стагнации вследствие пандемии Covid-19 испытали связанные с ним виды деятельности: транспорт (п. 1), сфера культуры, организации досуга и развлечений (п. 2), гостиничный бизнес (п. 5), общественное питание (п. 6), деятельность по организации конференций и выставок (п. 8).

На этом фоне важна селективная поддержка тех видов туризма, которые испытали наименьшее воздействие пандемийных трансформаций. И к такого рода видам туризма относится сельский туризм. Известно, что «российские туристы частично переключились с выездного туризма на различные формы отдыха дома ... В 2020-2021 годы эпидемиологическая обстановка будет серьезно сдерживать все виды туризма в мире и в России, что дает время для развития ... туризма с тем, чтобы расширить возможности полноценного отдыха внутри страны» [7, с. 2].

Развитие сельского туризма является одной из основ восстановления туристического бизнеса в целом, который в будущем может стать трансграничным, т.к. в РФ имеются уникальные сельские дестинации, весьма привлекательные для иностранных туристов. Это требует наращивания бюджетной поддержки сельского туризма. Между тем, сегодня она явно недостаточна. Так, по данным Ростуризма в 2018-2020 годах в сфере поддержки сельского туризма осуществлялось софинансирование и грантовая поддержка различных проектов сельского туризма: из федерального бюджета поддержку получили 26 субъектов на общую сумму свыше 67 млн. руб.; в 32-х регионах осуществлялась государственная поддержка сельского туризма путем реализации соответствующих муниципальных и региональных программ. Приведенные показатели, касающиеся господдержки, говорят о ее явной недостаточности.

Безусловно, такого рода активность должна быть продолжена и наращена в среднесрочной перспективе, потому как именно сейчас сельский туризм имеет уникальные возможности для развития, определяемые пандемическими условиями [3]. Следует также отметить, что пандемия оказала мощное влияние на социально-экономическую систему в целом, изменив структуру хозяйственной и социальной активности и фактически дав старт активной фазе цифровой революции [10]. Это также должно быть учтено при разработке и реализации мер поддержки сельского туризма.

В частности, мы предлагаем создание специальной цифровой платформы сельского туризма, на которой могли бы быть представлены турпродукты соответствующих участников этого рынка, осуществлялось бы их продвижение, рекламная и имиджевая поддержка, информирование потенциальных потребителей (сельских туристов), организовано обучение начинающих предпринимателей в сфере сельского туризма, здесь же возможно организовать общественный и государственный мониторинг услуг сельского туризма, обмен лучшими практиками и др. Эта цифровая платформа может быть как самостоятельной (т.е. специализирующейся на сельском туризме), так и интегрированной с уже существующими цифровыми платформами, созданными для продвижения продукции мелких сельхозпроизводителей. Отметим, что второй вариант соответствует существующей законодательной логике регулирования сельского туризма в России, согласно которой предоставлять эти услуги могут только сертифицированные сельхозпроизводители.

Такая платформа могла бы способствовать развитию сетевого сотрудничества между основными стей- 
кхолдерами сельского туризма, что благоприятно сказалось бы как на эффективности деятельности организаций, предоставляющих такие туристические услуги, так и на качестве этих услуг.

Внедрение цифровой платформы сельского туризма соответствует тенденции цифровой трансформации мировой экономики [17] (и отрасли туризма [2]), а также новым моделям производства и потребления услуг. Провайдерам и потребителям комфортнее общаться на платформах, которые позволяют создать единый канал взаимодействия и предлагают единые правила сотрудничества.

Отметим, что полагаться на глобальные туристические платформы для продвижения национальных продуктов в сфере сельского туризма нецелесообразно. Хотя для отдельных организаций, предоставляющих услуги сельского туризма, такое сотрудничество может быть полезным (поскольку международные платформы могут расширить целевую аудиторию таких организаций), в целом глобальные платформы препятствуют развитию национальных туристических продуктов (поскольку изымают ресурсы у национальной туристической отрасли) [24]. По этой причине необходимо создавать национальную платформу для продвижения российского сельского туризма. Такая платформа способствовала бы развитию сельского туризма на двух уровнях, формируя привлекательный образ нашей страны и ее отдельных регионов как дестинаций для сельского туризма, а также продвигая конкретные организации и их продукты.

\section{Зак^ючение}

Таким образом, сельский туризм, хотя и имеет длительную историю существования, является новой (с позиций правового регулирования) формой туризма для Российской Федерации. В условиях динамичных трансформаций социально-экономической системы, в том числе спровоцированных пандемией Covid-19, сельский туризм имеет хорошие перспективы развития и может выступить в качестве пропульсивного элемента туристического бизнеса. Для этого требуется более четкое описание его сущности, в том числе уточнение введенной федеральным законом трактовки этой категории, а также активизация государственной поддержки развития сельского туризма, как путем дополнительного финансирования соответствующих проектов, так и за счет административной и информационно-технологической поддержки.

\section{Эаявление \\ об ответственности авторов}

Авторы декларируют отсутствие конфликта интересов, связанных с публикацией данной статьи. Статья отражает результаты совместного исследования авторов, при этом авторский вклад распределен следующим образом: Плотников В.А.- постановка задачи исследования, координация исследовательских усилий, подготовка чистового текста статьи, Гамидова А.Э.- сбор исходных данных, их обработка, подготовка исходного (чернового) варианта статьи.

\section{ЛИТЕРАТУРА}

1. Волков С.К. Сельский туризм в РФ: тенденции и перспективы развития // Экономика, предпринимательство и право. 2012. № 6. С. 30 -38.

2. Воронова 0.В., Харева В.А., Хныкина Т.С. Современные тенденции развития рынка услуг Российской Федерации в условиях цифровой трансформации (на примере индустрии гостеприимства) // Международный научный журнал. 2019. № 1. С. 19-25.

3. Гамидова А.Э. Особенности регулирования сельского туризма в Российской Федерации и перспективы его развития // Перспективы развития аграрно-пищевых технологий в условиях Прикаспия и сопредельных территорий: материалы межгосударственной научно-практической конференции, 6 июля 2021 года (г. Волгоград, г. Элиста). Волгоград: Изд-во ГнУ НИИММП, 2021. С. 65-70.

4. Гамидова А.Э. Перспективы развития аграрного туризма в постпандемийный период // Теория и практика сервиса: экономика, социальная сфера, технологии. 2020. № 3 (45). С. 31-34.

5. Гамидова А.Э. Сельский туризм в постпандемийный период // Известия Санкт-Петербургского государственного экономического университета. 2021. № 1 (127). С. 162-166.

6. Гварлиани Т.Е., Бородин А.Н. Сельский и аграрный туризм как специфические виды туризма // Terra Economicus. 2011. Т. 9. № 4-3. С. 61-65.

7. Динамика спроса на туристические услуги в России на фоне пандемии COVID-19. Бюллетень о текущих тенденциях российской экономики. Вып. 68 / Аналитический центр при Правительстве Российской Федерации. М., 2020. 17 с.

8. Здоров А.Б. Комплексное развитие туризма в сельской местности // Проблемы прогнозирования. 2009. № 4 (115). С. 149-153.

9. Зырянов А.И., Семиглазова В.А. Сельский туризм: от географических конструктов к моделям развития // География и природные ресурсы. 2021. Т. 42. № 1 (165). С. 33-41.

10. Институциональная трансформация социально-экономических систем в условиях цифровизации: состояние, тренды, проблемы и перспективы / Вертакова Ю.В., Андросова И.В., Акулова Ю.А. и др. Курск, 2020. 294 с.

11. Карпова Г.А., Богданова И.М. Роль и место предпринимательства в сфере туристских услуг // Известия Санкт-Петербургского государственного экономического университета. 2019. № 3 (117). С. 74-80. 
12. Колпакиди Д.В. Актуальные подходы к развитию регионального туризма // Известия Санкт-Петербургского государственного экономического университета. 2020. № 5 (125). С. 130-138.

13. Лимонина И.Г., Ермакова Н.А. Опыт устойчивого природопользования на прибрежных территориях: рыболовство, туризм, аквакультура // Известия Санкт-Петербургского государственного экономического университета. 2019. № 6 (120). С. 83-89.

14. Миндлин Ю.Б. Особенности применения кластеров в региональном управлении // Менеджмент и бизнес-администрирование. 2014. № 2. С. 70-80.

15. Мирошниченко Т.А., Подгорская С.В. Современные тенденции и перспективы развития сельского туризма в России // Вестник Забайкальского государственного университета. 2021. Т. 27. № 3. С. 119-126.

16. Плотников В.А. Обеспечение конкурентоспособности российского предпринимательства // Экономика и управление. 2009 . № 10 (48). С. 23 -26.

17. Плотников В.А. Цифровизация как закономерный этап эволюции экономической системы // Экономическое возрождение России. 2020. № 2. С. 104115.

18. Плотников В.А., Федотова Г.В. Роль сельского туризма в возрождении регионов России // Туризм на сельских территориях: опыт, проблемы, перспективы. Сборник трудов III Международной научно-практической конференции. СПб., 2014. С. 149-153.

19. Саакян И.А. Влияние сферы туризма на сельские общины (на примере Республики Армения) // Известия Санкт-Петербургского государственного экономического университета. 2020. № 4 (124). С. 139-141.

20. Трухачев А.В. Концепции и модели развития сельского туризма за рубежом // Сервис в России и за рубежом. 2016. Т. 10. № 7 (68). С. $34-40$.

21. Фалилеева 0.Ю., Михайлова М.А. Роль сельского туризма в сохранении культурно-исторического наследия // Вестник Восточно-Сибирского государственного института культуры. 2021. № 1 (17). С. 103-108.

22. Формы стратегического партнерства: модели взаимодействия в регионе / Вертакова Ю.В., Ватутина 0.0., Андросова И.В. и др. Курск: Изд-во ЮЗГу, 2013. 298 c.

23. Яковенко И.М., Страчкова Н.В. Сельский туризм: систематизация понятия и осмысление тенденций // Геополитика и экогеодинамика регионов. 2021. T. 7. № 3. C. 154-168.

24. Gössling S., Lane B. Rural tourism and the development of Internet-based accommodation booking platforms: a study in the advantages, dangers and implications of innovation // Journal of Sustainable Tourism. V. 23. № 8-9. P. 1386-1403.

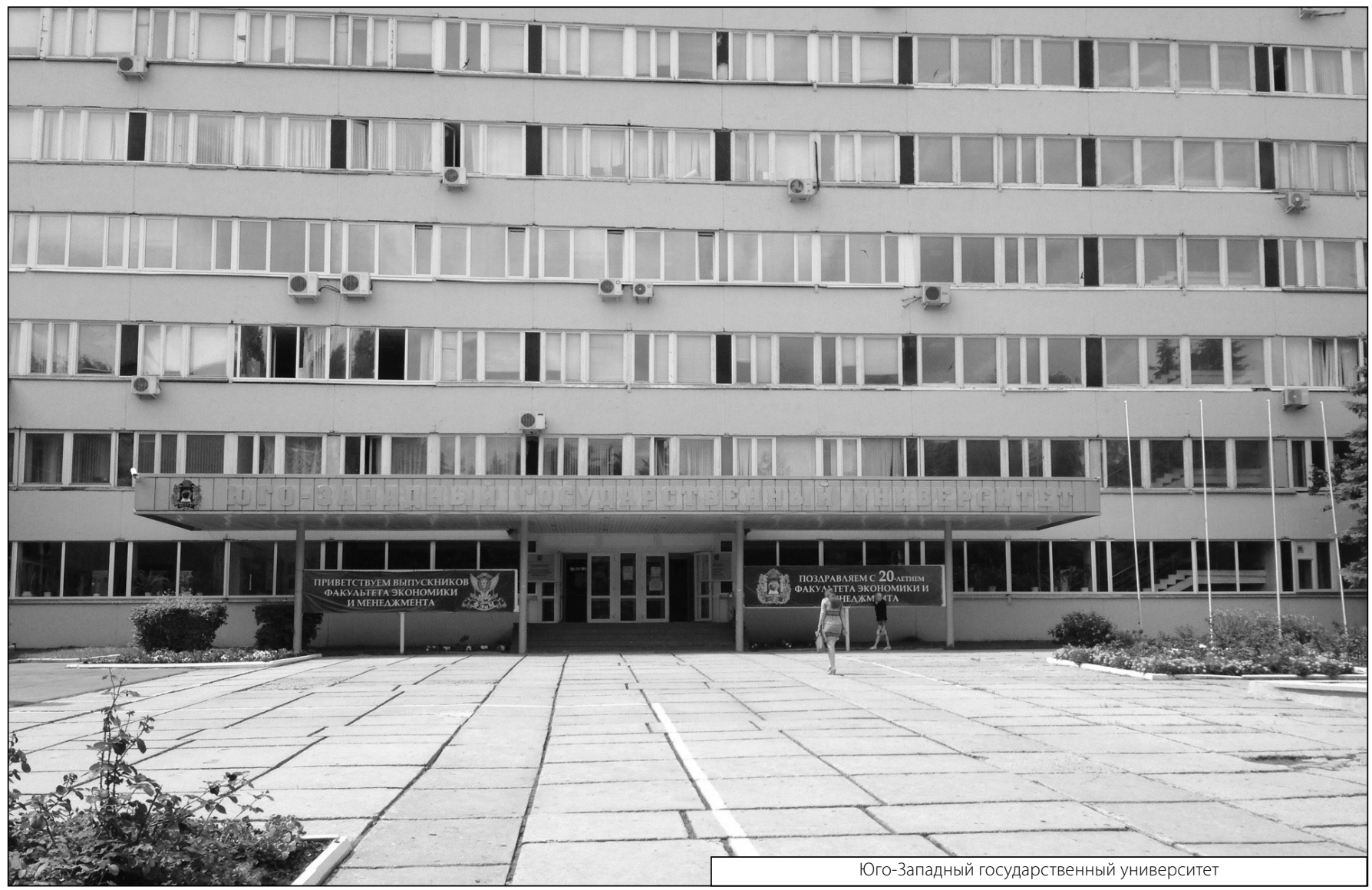

